\title{
HÁPTICA EM JOGOS: ORETORNO TÁTIL NO ESTÍMULO DA EMOÇÃO
} HAPTICS IN GAMES: THE TACTILE FEEDBACK IN
EMOTION STIMULUS

Guilherme Philippe Garcia Ferreira ${ }^{1}$ 


\section{Resumo}

O toque e a percepção cinestésica ${ }^{1}$ compõem uma grande parte das atividades dos jogos no mundo real. Seja empurrando, chutando, correndo, pulando ou puxando, quase sempre desempenhamos ações que possuem relações motoras e auxiliam na percepção do jogo como também, desencadeiam relações emocionais. Entretanto, em jogos digitais - embora exista o esforço constante de desenvolvedores para prover uma imersão complexa na narrativa - pouco se discutiu tecnicamente quanto ao papel das referências táteis no estímulo da emoção.

Este artigo apresenta uma revisão da literatura de estudos que consideram a háptica e a referência emocional do jogador. Também apresenta uma pesquisa aplicada para mapeamento preliminar de respostas emocionais em jogos. Observa que o retorno tátil promovido pela háptica pode oferecer uma relação interativa imersiva aprimorando a experiência emocional do jogador. Por fim conclui que os estudos sobre este tema ainda são incipientes e solicitam desenvolvimentos.
The touch and kinesthetic perception make up a large part of game activities in the real world. Pushing, kicking, running, jumping or pulling, we often perform actions that are related to motor skills and help in the awareness of the game, but also trigger emotional relationships. However, in digital games - although there is the constant effort of developers to provide a complex immersion into the narrative - little is discussed technically about the role of tactile references in emotion stimulus.

This article presents a literature review of studies that consider the haptic and the emotional reference of the player. It also presents an applied research for preliminary mapping of emotional responses in games. It attends that the tactile feedback promoted by haptics can offer an immersive interactive relationship enhancing the emotional experience of the player. Finally, it concludes that the studies on this topic are still incipient and request further developments.

Keywords: Haptics. Emotion. Game.

Palavras-Chave: Háptica. Emoção. Jogos.

1 Cinestesia ou propriocepção: Percepção ou sensibilidade da posição, deslocamento, equilíbrio, peso e distribuição do próprio corpo e das suas partes. (PRIBERAM, 2015)

\footnotetext{
1 Universidade Federal do Paraná

guilhermepgf@gmail.com
}

ISSN: 1808-3129 


\section{INTRODUÇÃO}

As plataformas utilizadas para o desenvolvimento de jogos digitais apresentaram um desenvolvimento exponencial nas últimas décadas. Acompanhando o ritmo de atualização de hardwares e softwares, os jogos digitais são lançados regularmente contemplando gráficos detalhados, inteligência artificial e mecanismos de resposta complexos. Embora os jogos digitais apresentem diversos segmentos de pesquisa e desenvolvimento, ainda existem pesquisas em busca de uma definição básica para jogo. Alguns pesquisadores identificados ao longo da revisão da literatura recorrem a (HUIZINGA, 1971) que discorre sobre as funções e significâncias do jogo e seu papel social. Para ele

"mesmo em suas formas mais simples, ao nível animal, o jogo é mais do que um fenômeno fisiológico ou um reflexo psicológico. Ultrapassa os limites da atividade puramente física ou biológica. É uma função significante, isto é, encerra um determinado sentido. No jogo existe alguma coisa "em jogo" que transcende as necessidades imediatas da vida e confere um sentido à ação." (HUIZINGA, 1971 p. 6)

O dicionário (MICHAELIS, 2015) promove, dentre outras, as seguintes definições de jogo:

\footnotetext{
“jo.go sm (lat jocu) 1 Brincadeira, divertimento, folguedo. 2 Passatempo, em que de ordinário se arrisca dinheiro, ou outra coisa. 3 Divertimento ou exercício de crianças, em que elas fazem prova da sua habilidade, destreza ou astúcia. $4 \mathrm{Ma}-$ neira de jogar. 5 Conjunto de regras a observar, quando se joga(...) " [2]
}

Neste artigo utilizou/se da ótica de (SCHELL, 2008), que apresenta os jogos como uma atividade recreativa de resolução de problemas, composta de aspectos estéticos, tecnológicos, mecânicos e de narrativa. De acordo com (Braga 2008, p. 52):

\footnotetext{
"o grande trunfo das atividades lúdicas é o fato de estarem centradas na emoção e no prazer, mesmo quando o jogo possa trazer alguma angústia ou sofrimento. " Em (HUDLICKA, 2009)
}

observa-se que as emoções possuem um papel central na experiência do usuário em games, aplicações para educação, terapias de reabilitação, como também treinamento e simulações. Os jogos digitais oferecem esta atividade através de uma interface apresentada em tela, componentes de áudio e dispositivos de entrada e interação com usuário tais como controladores e mecanismos de rastreio.

Neste contexto se inserem os controladores para jogos capazes de oferecer, através de um hardware acionado por um software, o retorno tátil e/ou cinestésico aos jogadores. Estes controladores que podem oferecer o retorno de força e movimento são denominados tecnicamente como dispositivos hápticos. A norma "ISO 9241-910" de 2011 define a háptica como sendo a estimulação sensorial motora de músculos, tendões e juntas. Segundo a norma, esta estimulação pode ser observada através da simulação do toque, da geração de referências cinestésicas e com base na vibro-ativação.

O uso de elementos hápticos nos jogos digitais, remontam à década de 1980 disseminado em máquinas de jogos em gabinetes (como os arcades e/ou fliperamas). 
Segundo (AUDIOKINETIC, 2008) o processo para a aplicação de referenciais hápticos em jogos ocorreu durante muito tempo por meio de tentativa e erro. A aparente falta de documentação que esclareça como o retorno háptico estimula a percepção e estado emocional dos usuários sugere um caráter ainda incipiente deste recurso. Para (AUDIOKINETIC, 2008) esta abordagem supostamente de tentativa e erro no desenvolvimento de interações hápticas em jogos pode demandar uma atividade intensiva dos programadores e designers em identificar estímulos adequados a narrativa e a expectativa de resposta emocional do usuário.

Observa-se que não está esclarecido como é dada a relação emocional dos usuários frente ao uso do retorno tátil-cinestésico. Desta forma, é possível argumentar sobre a existência de uma lacuna frente ao uso atual de dispositivos hápticos em jogos digitais que deve ser investigada.

Compreendendo este quadro geral, e motivado pela coletânea ainda incipiente de documentos tratando sobre este assunto o presente artigo apresenta, inicialmente, uma revisão semi-estruturada da literatura que buscou elucidar se o retorno tátilcinestésico promovido pela háptica aplicada aos jogos pode oferecer uma relação interativa com maior imersão sensorial aprimorando a experiência emocional do jogador. Por fim, apresenta os resultados de um questionário aplicado a um grupo de 15 usuários de jogos que dispõem de retorno háptico (por vibração ou força) através dos controladores.

\section{DOCUMENTOS CONTEMPLADOS}

A revisão semi-estruturada da literatura foi utilizada por sua adequação a uma pesquisa com objetivo exploratório para a qual os conteúdos são pouco recorrentes e não foram identificados através de uma revisão estruturada ou sistemática. $O$ questionamento base da revisão apresentada foi: Como os temas Háptica, Jogos e Emoção são contempladas em pesquisas atuais? Para a superação desta dúvida a revisão buscou documentos disponibilizados nos últimos dez anos em meio eletrônico. A seleção do referencial ocorreu através da leitura qualitativa dos documentos localizados através da combinação de termos como (háptica, emoção, jogos, força, estímulo) e seus equivalentes em inglês (haptics, emotion, games, force feedback, stimulus), estes termos foram aplicados a portais de indexação como ScienceDirect, IEEE, Google Scholar, Periódicos Capes, SCielo, e site do evento SBGames. As seções na sequência apresentam sinteticamente os resultados destas revisões que contemplaram 25 documentos e a normativa "ISO 9241-910".

\section{JOGOS}

Nas últimas décadas, a emergência de novas tecnologias e a capacidade de digitalização dos jogos redefiniram o papel do jogo na sociedade. (HUIZINGA, 1971) des- 
creve os jogos como uma atividade lúdica, praticada dentro de certos limites e regras previamente estabelecidas. Segundo os autores, os jogos proporcionam um momento de diversão, de natureza livre e espontânea. (PINTO NETO e SOARES, 2006) expandem este conceito e argumentam que os jogos de computador, vídeo game, celular, entre outras plataformas, podem ser definidos como uma atividade lúdica, que apresenta um sistema de regras próprio e contempla espaços de interação construídos no meio digital. Os jogos digitais admitem uma repercussão global, possibilitando o acesso de jogadores remotos em ambientes compartilhados e a abertura de diálogo com diferentes culturas de forma participativa.

Os elementos que constituem a mecânica dos jogos são descritos por (SCHELL, 2008) como espaço, objetos, atributos e estados, ações, regras, habilidades e a chance que dá características do fator sorte nos jogos. De acordo com (BRANDÃO et al., 2010) os jogos eletrônicos proporcionam a percepção emocional ao oferecer uma narrativa em componente simulado aonde se pode agir e reagir, observar o que acontece (em primeira e terceira pessoa) e permanecer neste contexto até que uma perturbação interna ou externa remova o usuário da imersão proporcionada. Para (GOUVEIA, 2009) os espaços virtuais e as narrativas viabilizadas pelos jogos, tais como as experiências participativas em softwares multiusuários, proporcionam o desenvolvimento de enredos lúdicos em que o jogador atua diretamente no ambiente e história.

\section{EMOÇÃO}

Segundo (HUDLICKA, 2009) existem diversos conceitos correlatos quanto ao que seria a emoção, uma característica convergente identificada pelo autor descreve que as emoções são apresentadas em momentos instantâneos que podem durar de segundos a minutos. Este aspecto da emoção, reflete a percepção do usuário frente a seu papel no mundo, aspectos cognitivos e tendências comportamentais. $O$ estudo de (MIHELJ et al., 2009) indica que existem evidências científicas de que as emoções experimentadas enquanto são jogados os jogos digitais, apresentam respostas em aspectos fisiológicos que podem ser observados e mensurados para determinar se o usuário está passando por uma experiência positiva ou negativa durante o jogo.

Para (BASORI et al., 2009), os estudos da percepção emocional têm promovido o desenvolvimento de modelos de inteligência artificial que podem ser implantados em diferentes aplicações como jogos, agentes inteligentes e ferramentas robóticas. (ERMI e MÄYRÄ, 2005), sugerem que a experiência de jogo pode ser definida através das sensações dos usuários, os sentimentos, ações, pensamentos e também dos significados extraídos dos ambientes de jogo. (BASORI et al., 2009) apontam que, embora não existam modelos que possam representar toda a complexidade das emoções humanas, as pesquisas sugerem um vínculo de influência com as condições do ambiente e também pelas condições internas do usuário como expectativas e estados emocionais.

Os estudos de (ARCHAMBAULT et al., 2008) sugerem a possibilidade de motivar 
comportamentos e ações específicas através da emoção. Os autores observam que nos jovens o desenvolvimento emocional decorre das relações sociais e de experiências como a observação de padrões de comportamentos presentes na vida humana. Estes padrões podem ser simulados em ambiente digital. Características como o gestual, movimentação da boca, olhos e sobrancelhas podem ser implementados para direcionar a emoção percebida nos personagens digitais. Como exemplo (BASORI et al., 2007) identificaram jogos capazes de utilizar modelos tridimensionais simulando com maestria as reações emocionais humanas através de expressões.

(JONATHAN, 2007) faz um significativo apanhado sobre como os aspectos emocionais podem ser contemplados nos jogos digitais. $O$ trabalho se delineia na identificação de grandes áreas que podem ser destrinchadas para a compreensão da emoção nos jogos. Dentre as contribuições do seu trabalho, o autor apresenta oito entradas ou ativadores da emoção nos jogos digitais (Tabela 1).

\begin{tabular}{|c|c|c|}
\hline \multicolumn{3}{|c|}{ Papel da Audiência } \\
\hline $\begin{array}{l}\text { Tipos de } \\
\underline{\text { Emocão }}\end{array}$ & $\begin{array}{l}\text { Observador- } \\
\text { participante }\end{array}$ & Ator-participante \\
\hline Ambiente & Ambiente sensorial & Propriocepção \\
\hline Narrativa & $\begin{array}{c}\text { Situações da } \\
\text { narrativa }\end{array}$ & Roleplay \\
\hline Jogo & Eventos do Jogo & Gameplay \\
\hline Artefato & Design & Arte \\
\hline
\end{tabular}

A proposta de Jonathan (JONATHAN, 2007) permite envolver os estímulos clássicos como som, vídeo e eventos do jogo em entradas que destacam o papel do usuário frente a atividade, o ambiente cognitivo, a narrativa do jogo, os eventos e os objetos constituintes do mundo digital.

(HUDLICKA, 2009) relata que a emoção em jogos começou a ser tratada de forma específica por uma área denominada computação afetiva. Neste contexto, utilizam-se três conhecimentos centrais: a) a percepção da emoção e reconhecimento pela máquina; b) os modelos computacionais da emoção e c) a expressão da emoção pelos agentes de interação e robôs na construção da informação. A computação afetiva discute principalmente a interface bidimensional entre usuário e sistema, mas novos segmentos de pesquisa como a háptica afetiva iniciam o discurso com foco nas referências emocionais promovidas por hardwares.

\section{HÁPTICA}

O trabalho de (O'MALLEY e GUPTA, 2008) define a percepção háptica como o processo de aquisição, interpretação, seleção e organização da informação senso- 
rial tátil. Para os autores, este processo é composto de a) percepção tátil, que são as sensações percebidas pelos receptores da pele; b) cinestésica, que compreende o sentido da força em músculos e tendões e c) propriocepção, que compreende a identificação do posicionamento do corpo quanto a si mesmo e permite o controle adequado dos membros e articulações.

Em (RODRIGUES, 2011) é apresentado um diagrama de visualização (Figura 1) que permite observar como a háptica atua na interação homem-computador em comparação com um controlador comum. Verifica-se no diagrama que a apropriação de um referencial tátil-cinestésico pelo usuário ocorre concomitante a atividade gestual esta, por sua vez, garante a entrada de dados no sistema computacional que afere informações como posição, velocidade e força de ação do operador frente a referência adotada.

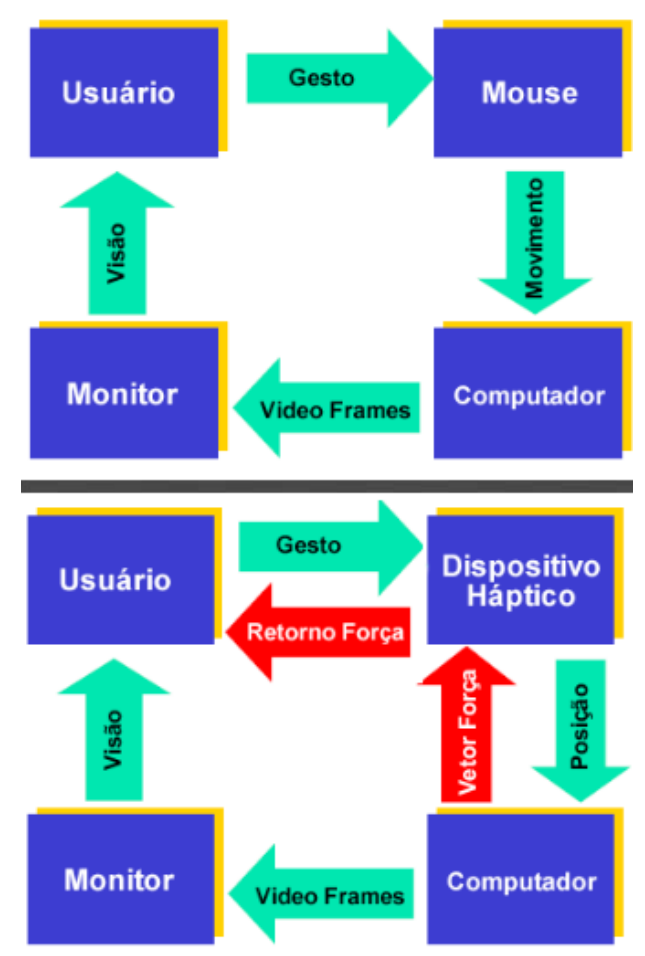

Figura 1: Interação Mouse-Háptica

Fonte: Extraído de Rodrigues (RODRIGUES, 2011)

Tratando das interações possíveis através de sistemas hápticos existem diferentes modelos de dispositivos hápticos que provêm capacidades distintas de interação e retorno, tais como: "retorno de apertar (grip feedback), retorno de segurar (grasp feedback), retorno de força (force feedback) e retorno tátil (tactile feedback)", segundo (FARIAS et al., 2006, p. 3).

\section{HÁPTICA EM JOGOS}

O toque segundo Rodrigues (RODRIGUES, 2011), pode ser entendido como o 
único dos cinco sentidos humanos considerado bidirecional, uma vez que recebe e envia informações. Ao realizar um toque, uma força é aplicada sobre algo e sua resultante é percebida por quem a aplicou. Assim, devido às características do sistema sensorial tátil, realizar ou perceber um toque depende necessariamente do contato direto com o objeto tocado. Observa-se que o toque desempenha um papel crucial na construção dos comportamentos sociais e na capacidade de compreender o ambiente. Na infância é comum o uso dos receptores táteis (como as mãos e a boca) na aquisição de informação. Para (Rahman et al., 2010) o uso do toque desempenha papel de grande relevância na comunicação e interação social. Referências sócio-emocionais de contato físico como um aperto de mão, cócegas, um abraço são elementos cruciais para o desenvolvimento cognitivo.

De acordo com (BASORI et al., 2007) o desenvolvimento de relações emocionais através da háptica é uma forma de aferir, dentro do universo digital dos jogos, características das relações apresentadas no mundo real. Em (BAILENSON e YEE, 2008) é apresentado um contexto em que múltiplos usuários utilizam a háptica como forma de interação por contato. Os autores sugerem que compreender o papel das interações hápticas em um âmbito social permite um entendimento melhor dos padrões de interação háptica que estes sistemas podem promover. (MIHELJ et al., 2009) apontam que a imersão no ambiente digital é interdependente da tecnologia que, em tempo real, deve promover respostas ao operador em áudio, vídeo, rastreio do movimento da cabeça e corpo, como também oferecer os retornos táteis adequados ao usuário.

(Rahman et al., 2010) apresentam a interação háptica como um meio para estreitar a percepção entre o mundo real e o mundo virtual. Os autores estudam a aplicação de retorno háptico na interação entre avatares e elementos do ambiente no simulador Second Life. O estudo buscou identificar referências emocionais do toque que podem ser representadas através das ações e movimentos dos avatares. Os autores concluem que o uso da háptica em ambientes de comunicação não-verbal podem aprimorar a interação social como também as experiências de imersão do usuário no mundo virtual que se assemelham as expectativas do mundo real. Cabe observar também o trabalho de (BASORI et al., 2007), que utiliza um joystick háptico para promover através da vibro-ativação em momentos específicos da narrativa interações entre usuário e cenário digital. Os autores sugerem que o referencial do toque pode incitar processos cognitivos e emocionais.

Na sequência são demonstrados exemplos de dispositivos que podem prover o referencial háptico.

\section{DISPOSITIVOS DE INTERAÇÃO}

O trabalho de (VALENTE et al., 2008) sobre jogos para dispositivos móveis verifica que o uso da háptica em dispositivos controladores de jogos para o uso doméstico tornou-se comum a partir da década de 1990, promovendo relações entre usuário e jogo com experiência sensorial de retorno tátil. Atualmente muitos controladores de jogos já promovem relações hápticas de vibro-ativação (Figura 2), e há também modelos mais complexos com o retorno cinestésico de força. 


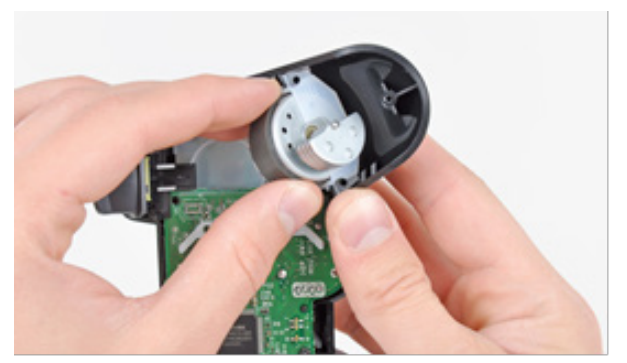

Figura 2: Controlador com peso descentralizado Fonte: Extraído de (BOOKHOLT, 2013)

O motor com vibro-ativação também é componente de dispositivos móveis como celulares e tablets, permitindo uma referência ativa da interface para o utilizador. Joysticks que permitem o retorno de força (Figuras 3, 4 e 6) apresentam custo de aquisição superior e são utilizados principalmente para simuladores de voo e corrida, como também treinamento em aplicações militares.

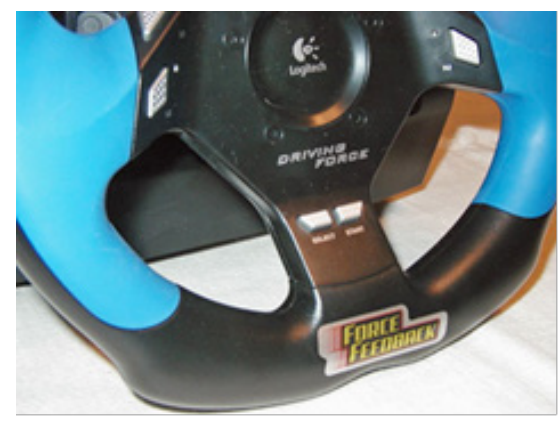

Figura 3: Joystick com retorno de força Fonte: Extraído de (MICROSOFT, 2000)

Este modelo de joystick promove o retorno de força em dois eixos, $\mathrm{X}$ e $\mathrm{Y}$. Entretanto, outros modelos de controladores possuem também o eixo $Z$ conforme exemplo a seguir (Figura 4).

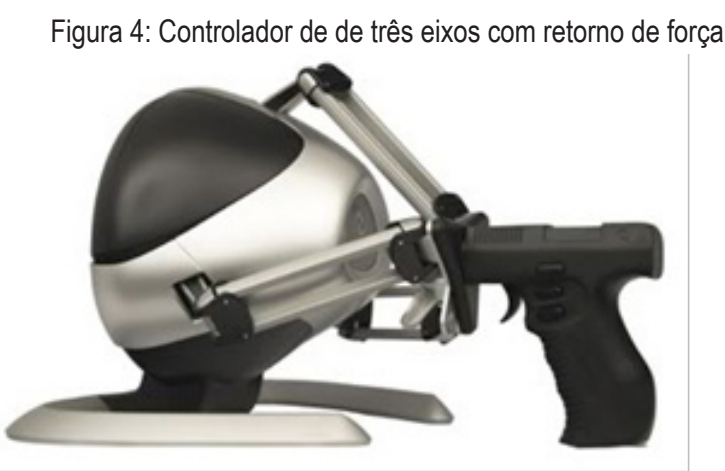

Fonte: Extraído de (NOVINT, 2012)

O controlador (NOVINT, 2012) foi desenvolvido para promover aplicações de desenvolvimento virtual e treinamento cirúrgico. Posteriormente foram disponibilizados adaptadores como o de punho de arma de fogo que visa o uso em jogos e si- 
muladores de tiro. Outros controladores possuem a forma de manches de aeronaves e volantes (Figura 5).

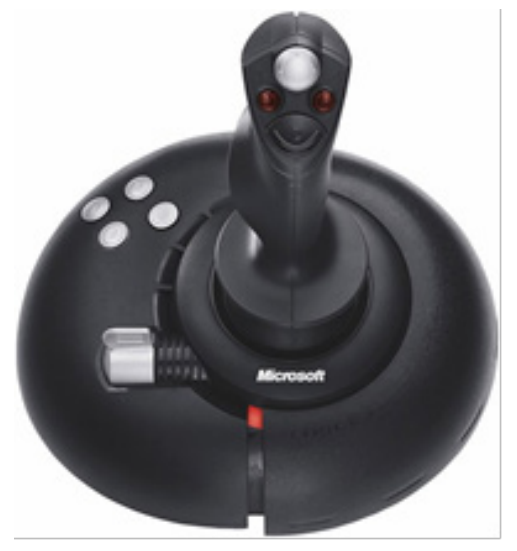

Figura 5: Volante com retorno de força

Fonte: Extraído de (LOGITECH, 2008)

Os volantes são uma das aplicações do retorno de força mais utilizadas atualmente. Este tipo de controlador é aplicado em simuladores de carro, embarcações e jogos de corrida e conta também com respostas vibro-ativadas. Na Alemanha, um grupo de pesquisadores do Hasso Plattner Institute utilizou da háptica em um experimento simulador de voo (Figura 6). Utilizando um display de alta resolução (OculusRift) com giroscópios que identificam a posição da cabeça do utilizador (CHENG et al., 2014).

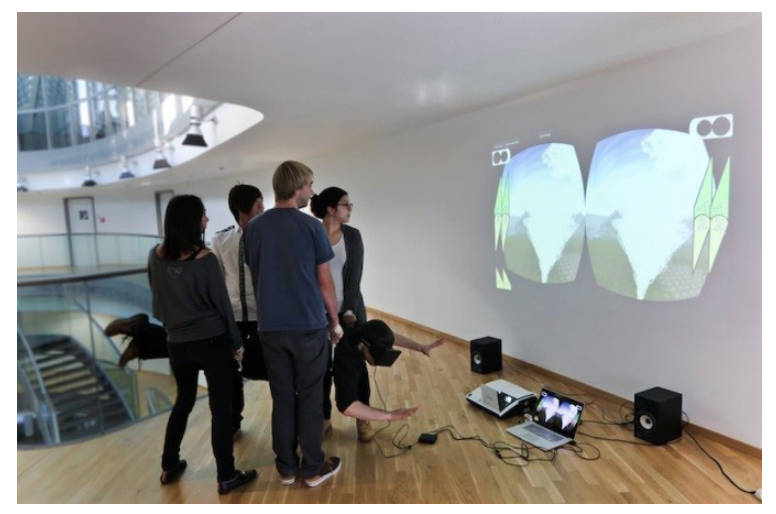

Figura 6: Simulação de resposta háptica Fonte: Extraído de (CHENG et al., 2014, p. 5)

No experimento o usuário sofre a ação háptica através dos colegas que orientados por instruções gráficas no vídeo verificam os movimentos que devem ser aplicados ao usuário. O dispositivo Reactivo Grip (Figura 7) da empresa Tatical Haptics ainda é um protótipo porém, durante o encontro IEEVR 2014 (Conferência IEEE Virtual Reality) recebeu o prêmio de melhor demonstração. 


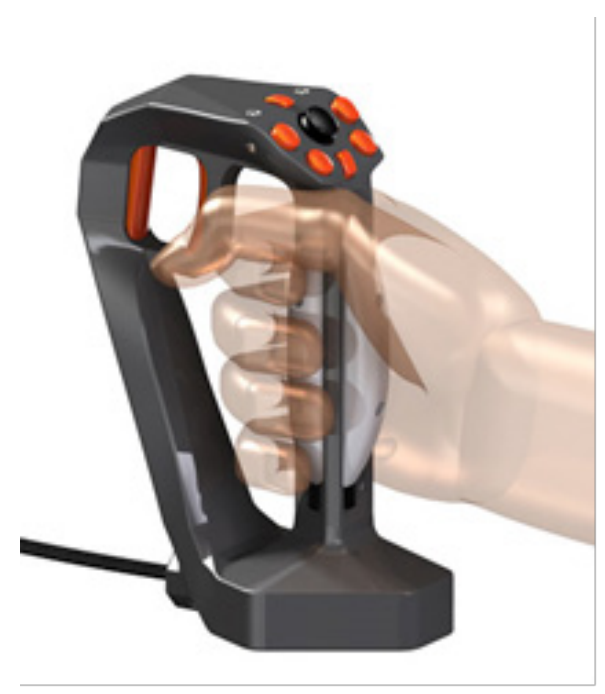

Figura 7: Controlador háptico com componentes móveis Fonte: Extraído de (TATICAL HAPTICS, 2014)

Contendo partes móveis o controlador permite exercer força na palma da mão do usuário promovendo interpretações táteis do cenário de jogo. (RAHMAN et al., 2010) sugerem que os dispositivos vestíveis poderão facilitar o uso destes elementos hápticos em ambientes que exijam flexibilidade e propõem o uso de uma jaqueta háptica com dispositivos vibro ativos dispostos ao longo da vestimenta. Os estudos identificados na revisão sugerem que novas formas de interação háptica estão em desenvolvimento e poderão a curto prazo suplantar parte das deficiências percebidas nos dispositivos atuais.

\section{O ESTÍMULO À EMOÇÃO}

A emoção nos jogos tem referências claras na construção de narrativas e roteiros derivadas da indústria do cinema. (SOARES de LIMA et al., 2010), apontam que os criadores de alguns jogos buscam desenvolver relações emocionais através de indicadores como: efeitos visuais; alteração na dinâmica da música e sons; e também comunicação entre personagens com base na situação global do jogador, status, habilidades e localização.

Em (FARIAS et al., 2006) uma bicicleta modificada foi utilizada como equipamento háptico para entrada de dados em um simulador de ciclismo. A háptica foi utilizada para simular imperfeições no percurso como também aumentar e reduzir o torque necessário para o movimento dos pedais em resposta ao ambiente de pedalada. Os usuários do experimento apontaram que a háptica gerou atratividade e também imersão promovendo interesse na atividade. No experimento de (RAHMAN et al., 2010) com a interface do jogo SecondLife aumentada com dispositivos hápticos, os usuários alegaram que gostariam de continuar utilizando esta modalidade de retorno caso fosse disponível.

De acordo com (BASORI et al., 2008) o estímulo háptico objetiva incrementar as 
relações emocionais do usuário com o ambiente de jogo ao qual se pretende imergir. Ao se referir ao jogo JamesBond 007, (RAVAJA et al., 2008) abordam o uso da háptica na comunicação de status do jogo:

- Quando o jogador é machucado o controlador vibra e também são utilizadas informações visuais e auditivas na tela;

- Quando o jogador é atingindo de forma fatal o controlador vibra com maior intensidade e tempo enquanto a tela utiliza do recurso de escurecimento escorrendo a cor vermelha por todo o monitor.

Segundo (AUDIOKINETIC, 2008) o uso de referencial háptico nos jogos se vincula a atividades informacionais que promovem o estado do personagem ou do ambiente digital ao usuário como:

- o estado de saúde;

- a colisão com um objeto invisível;

- a colisão objetos visíveis em jogo de corrida.

Também são simuladas as relações de retorno háptico de artefatos como:

- as rotações do motor em um carro;

- solavancos em uma estrada;

- a altitude e os empuxos de um avião;

- a força de aceleração ou desaceleração.

Os autores também apontam que o retorno háptico pode promover a surpresa no jogador ao ser acionado em momentos específicos do jogo:

- em um momento de tensão;

- ao fisgar um peixe;

- ao rebater uma bola em um simulador de esportes.

O trabalho de (ACKERMAN et al., 2010) verifica como as relações hápticas como peso, textura e dureza podem, de forma inconsciente, influenciar julgamentos e decisões, mesmo sob aspectos que não são diretamente relacionados a interação como eventos, situações e objetos.

\section{PESQUISA APLICADA}

Para uma observação piloto do comportamento do usuário frente a temática apresentada foi aplicado um questionário que objetivou identificar a relação emocional dos jogadores ao serem submetidos a um estímulo háptico e partindo desta identificação propor um mapeamento básico da percepção dos usuários da emoção em jogos. Foi utilizado triangulada a literatura e a percepção emocional do usuário sob ação da háptica. A coleta e a validação dos valores foi realizada de forma qualiquantitativa procurando identificar padrões que possam descrever se existe ou não uma relação diferenciada com o uso de retornos hápticos. Os dados foram coletados através de questionários encaminhados por correio eletrônico e investigadas as vivências dos jogadores com controladores com retorno háptico ou vibro ativo.

O questionário foi respondido por 15 usuários de jogos que experienciaram através de controladores variados o retorno de força ou vibração. A primeira ques- 
tão ("Você utiliza controladores de jogos com vibroativação e/ou retorno de força?") atuou como um possível filtro dos respondentes. Todos os participantes responderam positivamente. Os resultados da questão 2 ("Em quais classes de jogos você percebe maior envolvimento emocional?") podem ser observados no Gráfico 1.

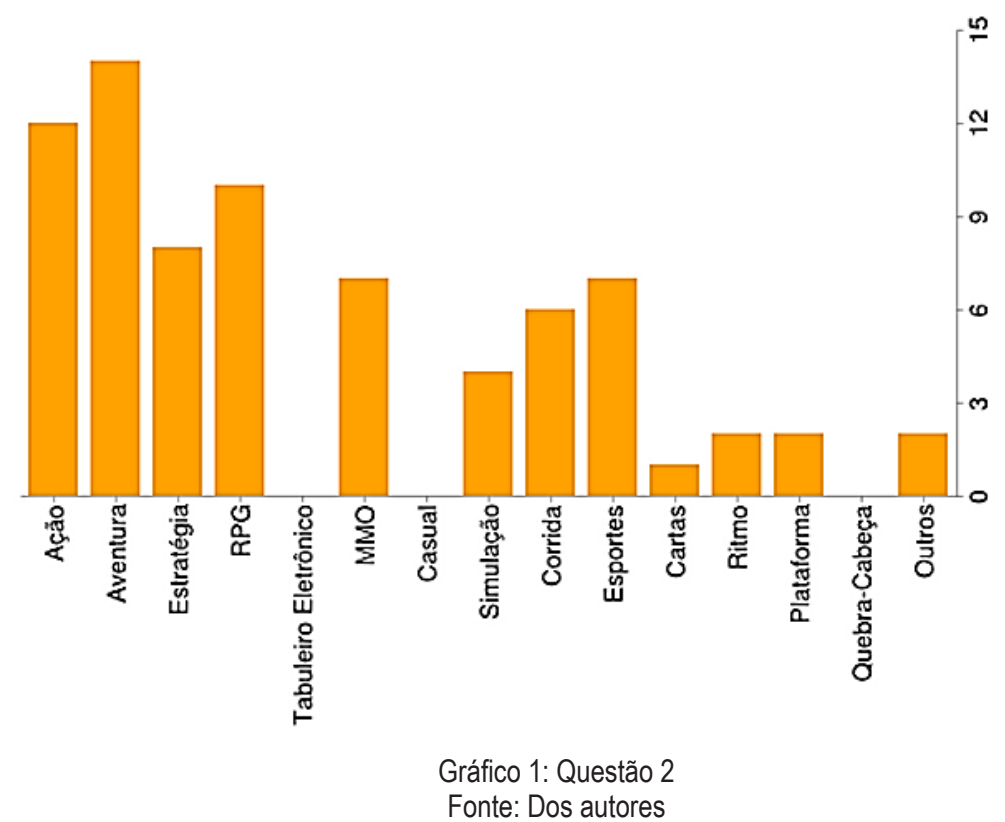

A questão 3, ("Quais emoções você GOSTA de sentir com os jogos?") busca relacionar o interesse dos jogadores em resposta emocional frente aos jogos utilizados. As respostas são apresentadas no Gráfico 2.

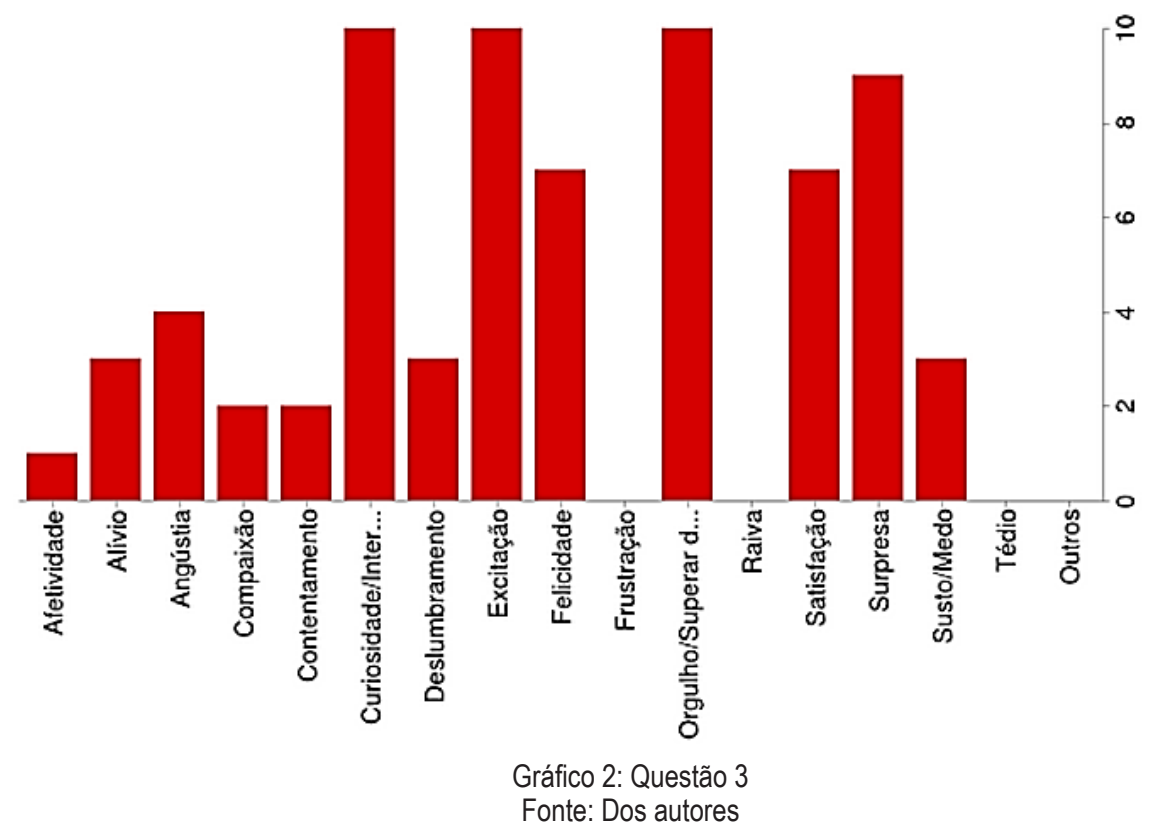

As respostas da questão 4 ("Quais emoções você NÃO GOSTA de sentir com os jogos?") são apresentadas no Gráfico 3. A questão busca relacionar o que não é de interesse dos jogadores em resposta emocional frente aos jogos utilizados. 


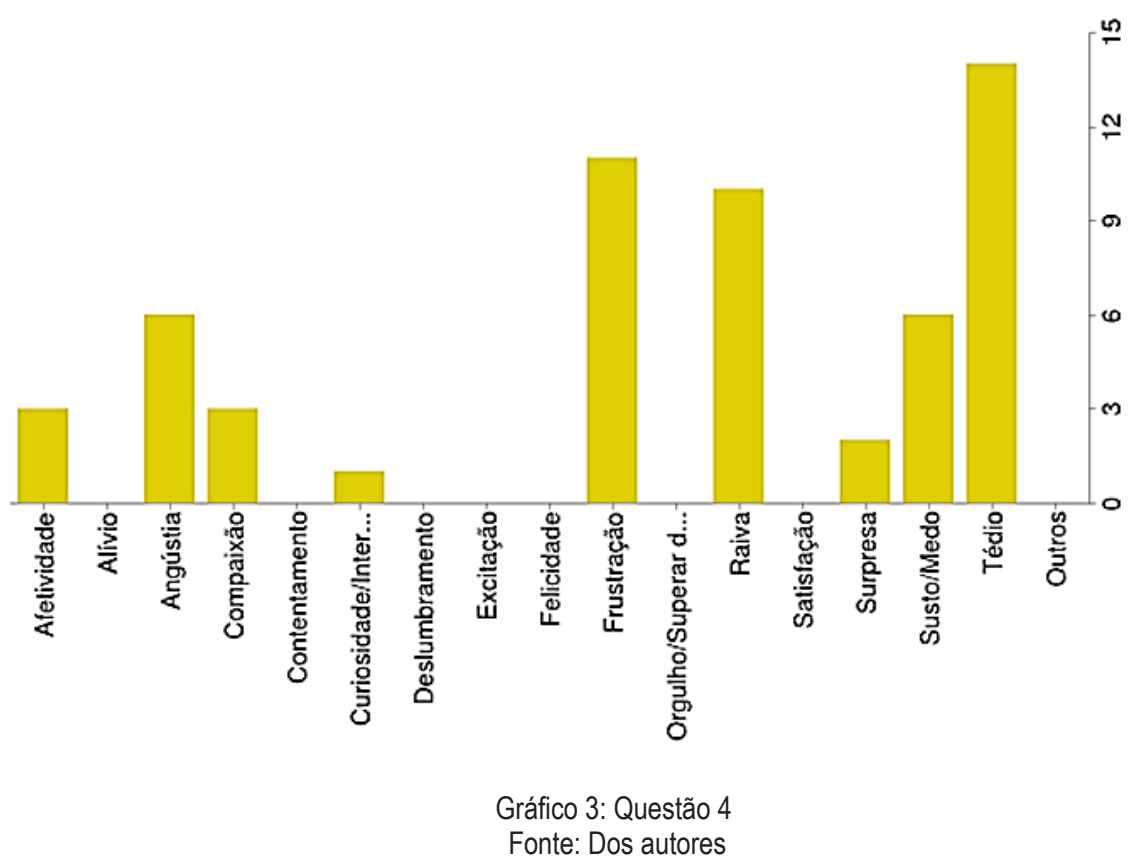

O Gráfico 4 apresenta as respostas da questão 5 ("Em quais classes de jogos você acredita que a vibração e/ou retorno de força proporciona maior imersão/ interação?"). A questão busca identificar a percepção geral dos usuários quanto ao retorno háptica.

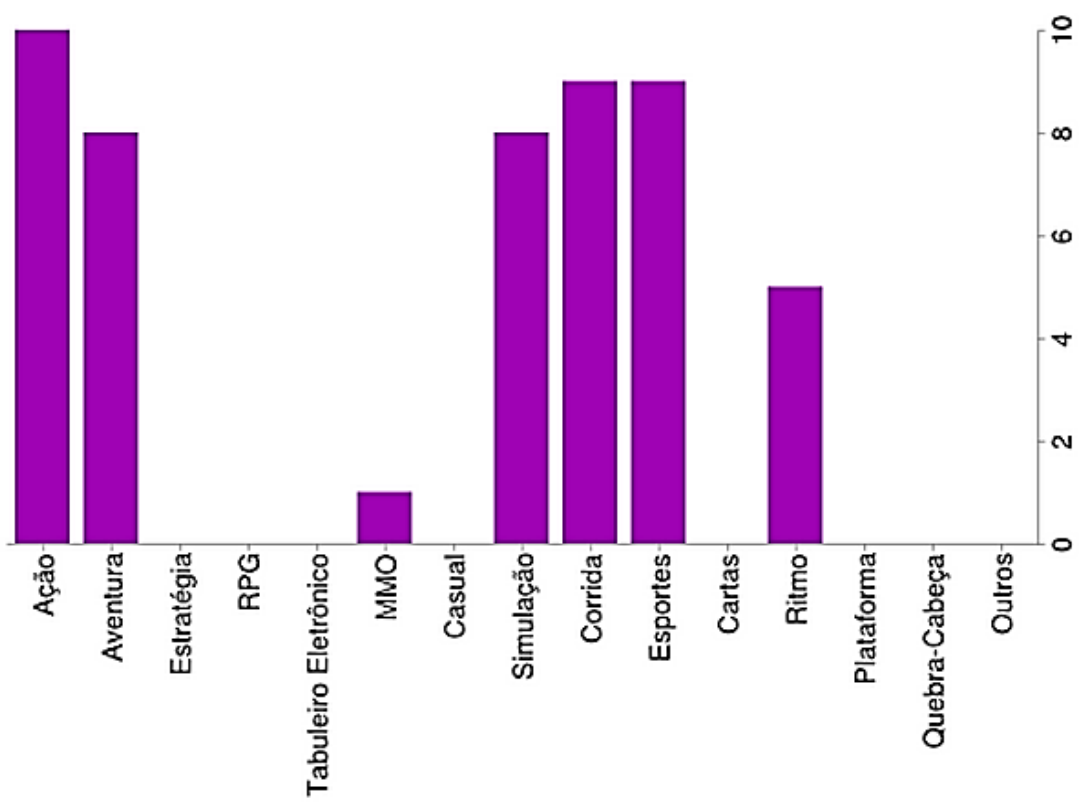

Gráfico 4: Questão 5

Fonte: Dos autores

A questão 6 ("Quais estímulos emocionais você percebeu nestes jogos através da vibração e/ou retorno de força?") busca correlacionar a ação háptica com o estímulo emocional. As respostas são apresentadas no Gráfico 5. 


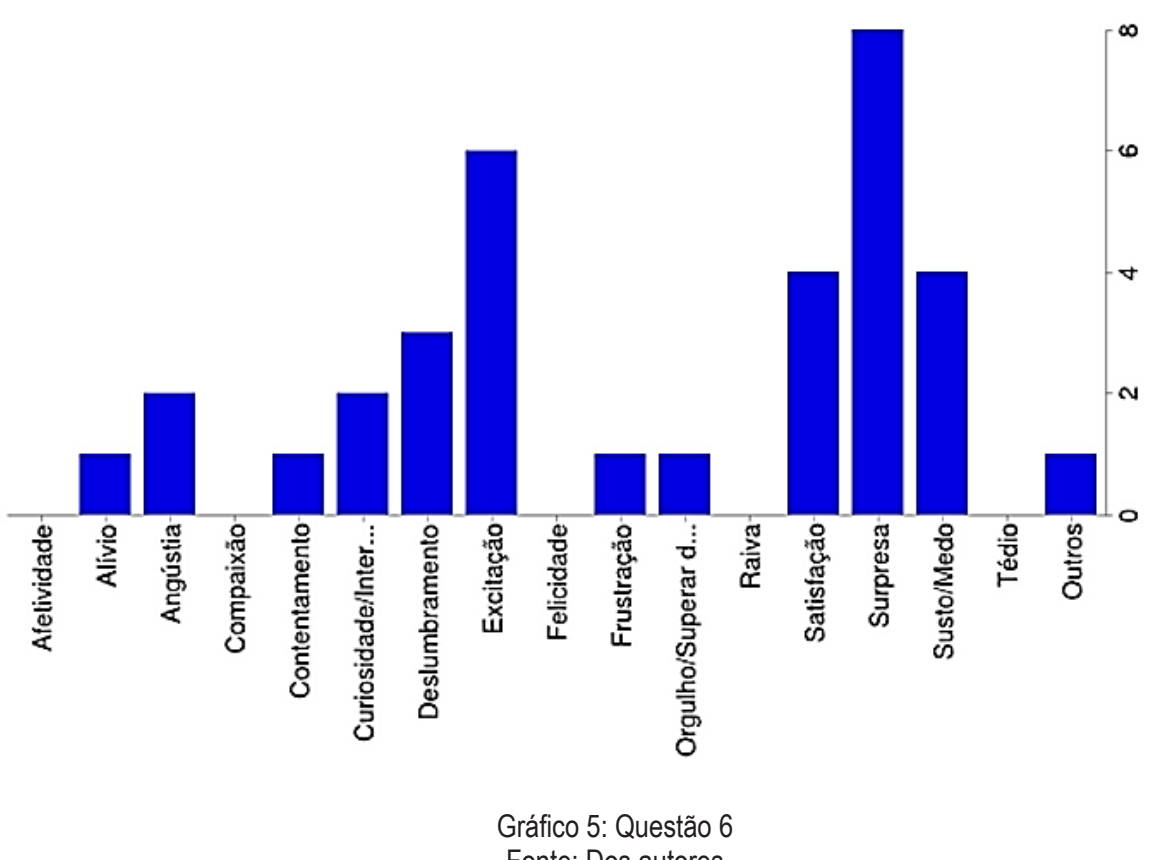

A questão 7 ("Você acredita que dispositivos com vibração e/ou retorno de força, permitem um envolvimento maior com o jogo?") teve apenas uma resposta negativa. Por fim, a questão 8 ("Descreva experiências ou percepções sobre o uso de controladores com vibração e/ou retorno de força em jogos.") foi aberta e buscou captar informações não contempladas através das perguntas fechadas. Apenas 7 dos 15 respondentes preencheram esta questão. As respostas são expostas sinteticamente:

O usuário 1 relatou que o referencial háptico foi melhor observado em jogos de futebol, por exemplo, para indicar um chute em trava. Também em jogos de tiro, quando o personagem é atingido ou quando ocorrem explosões próximas e também para aumentar a tensão dramática quando defrontado com perigos.

O usuário 2 relatou que não percebe grande diferença nos jogos com o uso da háptica, mas complementou citando Martin Lindstrom, escritor de marketing, sobre o uso de estímulos multissensoriais para promover maior envolvimento.

O usuário 3 relatou que teve contato com simuladores de voo e de automóvel e que as vibrações aliadas ao retorno de força trouxeram maior realidade à experiência digital.

O usuário 4 presenciou a háptica no console Wiimote ${ }^{2}$, e afirmou que percebeu maior excitação em relação a não dispor do retorno através da vibração.

O usuário 5 relatou que, em especial em jogos de sobrevivência, os estímulos puderam antecipar problemas e também favorecer o fator surpresa, tornando a imersão no cenário mais rica.

O usuário 6 apontou que não teve contato com controles com retorno de força. Para ele, apenas a vibração não favoreceu o retorno cinestésico mas estimulou a percepção de eventos nos jogos.

O usuário 7 não considerou a vibração fator crucial, mas afirmou que ao utilizar o Kinect ${ }^{3}$ por vezes não soube se o comando gestual foi capturado. Nesse caso, segundo o usuário, o retorno háptico poderia promover uma melhor resposta do sistema.

${ }^{2}$ Controlador utilizado para captura de movimento no console Wii da Nintendo

${ }^{3}$ Equipamento de captura de imagem utilizado no console Xbox da Microsoft 


\section{DISCUSSÃO DOS RESULTADOS}

O questionário, embora aplicado a um grupo restrito de usuários, permitiu observar aspectos gerais da emoção vinculada ao retorno háptico e a narrativa dos jogos. Pode-se ponderar que os usuários percebam maior envolvimento emocional em jogos de Ação, Aventura, Estratégia e RPG. Este dado é compatível com os autores pesquisados uma vez que mencionam a importância da narrativa nos jogos, e estes por sua vez apresentam características e regras específicas ao cenário vivenciado. Como mencionado por (BRANDÃO et al., 2010) a emoção nos jogos é estimulada pela possibilidade de ação e reação frente ao ambiente simulado.

(HUIZINGA, 1971) aponta que os jogos são momentos de diversão, assim características emocionais apontadas na Questão 2 como orgulho, felicidade, satisfação e felicidade, eram esperadas. Entretanto, alinhado ao discurso de (SCHELL, 2008) observou-se também a importância de emoções como a surpresa, a angústia e por fim o alívio, que podem ser compreendidas como momentos em que a narrativa apresenta desafios ao usuário no papel de ator-participante (JONATHAN, 2007).

Sensações notoriamente consideradas negativas como medo, raiva, frustação e tédio preferem ser evitadas pelos jogadores. Estes dados se alinham ao discurso de (BRAGA, 2008) ao afirmar que mesmo quando os jogos trazem emoções negativas, devem ser centrados na obtenção de prazer e na permanência do usuário na narrativa. Embora se compreenda que o medo possa estar presente em algumas classes de jogos, a raiva, frustração e tédio parecem se vincular a desafios incorretamente dimensionados que extrapolam a habilidade do usuário, como também demonstram possíveis falhas na dinâmica.

A Questão 5 sugere que os dispositivos hápticos proporcionam maior imersão em jogos de Ação, Aventura, Corrida, Esportes e Simuladores. Os resultados obtidos nesta questão estão próximos aos estudos apresentados (AUDIOKINETIC, 2008) que vinculam os retornos hápticos a momentos específicos de jogos usualmente vinculados as classes destacadas pelos respondentes. A não seleção da classe de jogos RPG (Role Playing Game) por sua vez, pode destacar que os dispositivos hápticos ou as repostas de força fornecidas pelos jogos ou controladores atuais ainda não são capazes de proporcionar vínculos afetivos com a narrativa, conforme discutido por (HUDLICKA, 2009).

Ao questionar que tipo de estímulos emocionais a háptica pode gerar (Questão 6), verificou-se que o medo ou o susto é um componente deste retorno sensorial, em conjunto com a surpresa, a satisfação e a emoção. A afetividade nesta questão também não foi apontada como ponto de destaque pelos respondentes. Se observarmos as escolhas apontadas na Questão 5, Ação, Aventura, Corrida, Esportes e Simuladores, pode-se ponderar que três classes de jogos destacadas Corrida, Esportes e Simuladores são prioritariamente técnicas, e os jogos de Ação e Aventura embora possam se valer de narrativas complexas muitas vezes não possuem situações narrativas complexas como o caso dos RPGs.

Os respondentes apontaram na Questão 7, que os jogos podem proporcionar maior imersão ao utilizar estímulos hápticos. Como dito em (Rahman et al., 2010) 
esta interação pode aproximar o mundo virtual do real e aprimorar a interação social. A Questão 8 em aberto, veio a corroborar com os dados identificados ao longo da pesquisa. As respostas destacam a importância e a incipiência deste estímulo no universo dos jogos. 


\section{CONSIDERAÇÕES FINAIS}

Foi possível identificar que o uso do referencial háptico nos jogos aparentemente, pois considera-se aqui apenas o corpo de documentos identificados, não dispõe de parâmetros especificados ou diretrizes que permitam a definição de guias de aplicação. É provável que estes se existirem estejam sob o domínio dos desenvolvedores, não sendo disponibilizados ao público geral. No que se refere à háptica aplicada em jogos como estímulo emocional, sugere-se que futuras pesquisas busquem identificar e correlacionar as referências táteis-cinestésicas que promovam respostas emocionais nos usuários. Nesse sentido, ainda não está claro qual tipo de emoção é recorrente para determinada modalidade de estímulo. Assim são necessárias novas investigações incluindo estudos relativos a frequências de vibro-ativação e percepção cognitiva e emocional dos usuários.

Por fim, assim como observado por (RAVAJA et al., 2008), há sempre uma probabilidade de que respostas para eventos virtuais de jogos sejam diferentes daquelas para eventos reais. Sendo necessários aprofundamentos para compreender possíveis disparidades cognitivas entre objetos reais e virtuais. Os resultados aqui obtidos apontam a háptica como um campo de pesquisa novo e em desenvolvimento. Observa-se que somente a poucos anos a háptica tem sido pesquisada de modo formal e aprofundada na academia em detrimento de outras linhas de pesquisa clássicas como os jogos ou a emoção. O tema da aplicação da háptica em jogos possibilita o tratamento de conhecimentos interdisciplinares para sua consolidação, a exemplo da narrativa e capacidade interativa dos jogos digitais.

Por fim, através do referencial teórico obtido na revisão pode-se identificar linhas de pesquisa emergentes como a computação afetiva, a háptica afetiva, e também do design emocional que podem ser contempladas em trabalhos futuros para maior aprofundamento do tema. Sugere-se ainda a aplicação de experimentos com diferentes modalidades de retorno de força e vibração, em cenário de jogos diversos, e dispositivos de mensuração que possam estimar a resposta emocional imediata dos usuários, como também o papel na alteração de parâmetros destes dispositivos frente a percepção.

\section{AGRADECIMENTOS}

À CAPES pela bolsa de Demanda Social - Doutorado

\section{REFERÊNCIAS}

Ackerman, J.M., Nocera, C.C., Bargh, J.A., 2010. Incidental Haptic Sensations Influence Social Judgments and Decisions. Science 328, 1712-1715. doi:10.1126/science.1189993 Archambault, D., Ossmann, R., Miesenberger, K., 2008. Towards Generalised Accessibility of Computer Games Introduction to the Special Thematic Session, in: Miesenberger, K., Klaus, J., Zagler, W., Karshmer, A. (Eds.), Computers Helping People with Special Needs, Lecture Notes in Computer Science. Springer Berlin Heidelberg, pp. 542-544. 
Audiokinetic, 2008. Force Feedback in Video Games. Audiokinetic Inc 6.

Bailenson, J.N., Yee, N., 2008. Virtual interpersonal touch: Haptic interaction and copresence in collaborative virtual environments. Multimed. Tools Appl. 37, 5-14. doi:10.1007/s11042-007-0171-2

Basori, A.H., Bade, A., Sunar, M.S., Daman, D., Saari, N., 2009. Haptic Vibration for Emotional Expression of Avatar to Enhance the Realism of Virtual Reality, in: Computer Technology and Development, 2009. ICCTD '09. International Conference on. Presented at the Computer Technology and Development, 2009. ICCTD '09. International Conference on, pp. 416-420. doi:10.1109/ICCTD.2009.132

Basori, A.H., Daman, D., Bade, A., Sunar, M.S., Saari, N., 2008. The feasibility of human haptic emotion as a feature to enhance interactivity and immersiveness on virtual reality game. ACM Press, p. 1. doi:10.1145/1477862.1477910

Basori, A.H., Daman, D., Sunar, M.S., Bade, A., 2007. The Potential of Human Haptic Emotion as Technique for Virtual Human Characters Movement to Augment Interactivity in Virtual Reality Game. He Int. J. Virtual Real. 6.

Bookholt, 2013 in Ifixt. Disponível em: https:/www.ifixit.com/Guide/DualShock+3+Vibration+Motors+Replacement/3254, Acessado em: 03/03/2015

Braga, M.E. de M., 2008. Brincando de Deus: jogos comunicacionais e uma nova percepção de mundo a partir da jogabilidade. Simpósio Bras. Games E Entretenimento Digit. 10. Brandão, R.P., Bittencourt, M.I.G. de F., Vilhena, J. de, 2010. A mágica do jogo e o potencial do brincar. Simpósio Bras. Jogos E Entretenimento Digit. Proc. 11.

Cheng, Lühne, Lopes, Sterz, Baudisch, 2014. Haptic Turk: a Motion Platform Based on People. Conf. Hum. Factors Comput. Syst.

Ermi, L., Mäyrä, F., 2005. Fundamental components of the gameplay experience: Analising Immersion. Digit. Games Res. Assoc. Second Conf.

Farias, Daliton, Moura, Teixeira, Costa, Dias, Teichrieb, Kelner, 2006. Um Estudo de Caso sobre a Construção e a Integração de Dispositivos Hápticos com Aplicações Interativas. An. Simpósio Bras. Jogos Comput. E Entretenimento Digit. 10.

Gouveia, P., 2009. Identidades em continuum, design de sistemas inclusivos nos MMORPGs. VIII Simpósio Bras. Jogos E Entretenimento Digit. Proc.

Hudlicka, E., 2009. Affective game engines: motivation and requirements. ACM Press, p. 299. doi:10.1145/1536513.1536565

Huizinga, J., 1971. Homo ludens: o jogo como elemento da cultura. Editora da Universidade de S. Paulo, Editora Perspectiva.

ISO 9241-910 (ISO/TC 159 Ergonomics), 2011. ISO - International Organization for Standardization. ABNT - Associação Brasileira de Normas Técnicas, Catálogo.

Jonathan, F., 2007. Eight Ways Videogames Generate Emotion, in: Situated Play. The University of Tokyo. pp.831-835

Logitech. Driving Force Logitech Force Feedback. Logitech Group, 2008. Produto

Michaelis, "jogo", in Dicionário Moderno da Língua Portuguesa, 2009, Disponível em: http://michaelis.uol.com.br/moderno/portugues/definicao/jogo\%20 988091.html Acessado em: $10 / 03 / 2015$

Microsoft. Joystick SideWinder Force Feedback 2. Microsoft Corporation, 2000. Produto Mihelj, M., Novak, D., Munih, M., 2009. Emotion-aware system for upper extremity rehabilitation, in: Virtual Rehabilitation International Conference, 2009. Presented at 
the Virtual Rehabilitation International Conference, 2009, pp. 160-165. doi:10.1109/ ICVR.2009.5174225

Novint. Gun Grip for Novint Falcon 3D Touch. Novint Technologies Inc, 2012. Produto O'Malley, M.K., Gupta, A., 2008. Haptic interfaces. HCI GUI Des. Haptic Speech Olfactory Nontradit. Interfaces pp.25-74.

Pinto Neto, Z.T., Soares, F.R., 2006. Concepção visual de personagens para jogos em ambientes virtuais: Um paralelo entre o psicológico e o visual. Simpósio Bras. Games E Entretenimento Digit. 8.

Priberam, "propriocepção", in Dicionário Priberam da Língua Portuguesa, 2015, Disponível em: http://www.priberam.pt/dlpo/ propriocep\%C3\%A7\%C3\%A3o Acessado em: 10/03/2015 Rahman, A.S.M.M., Hossain, S.K.A., Saddik, A.E., 2010. Bridging the Gap between Virtual and Real World by Bringing an Interpersonal Haptic Communication System in Second Life, in: Multimedia (ISM), 2010 IEEE International Symposium on. Presented at the Multimedia (ISM), 2010 IEEE International Symposium on, pp. 228-235. doi:10.1109/ISM.2010.40

Ravaja, N., Turpeinen, M., Saari, T., Puttonen, S., Keltikangas-Järvinen, L., 2008. The psychophysiology of James Bond: Phasic emotional responses to violent video game events. Emotion 8, 114-120. doi:10.1037/1528-3542.8.1.114

Rodrigues, H.F., 2011. Aplicando Sistemas Hápticos em Serious Games: Um Jogo para a Educação em Higiene Bucal. Universidade Fe deral da Paraíba, João Pessoa.

Schell, J., 2008. The art of game design: a book of lenses. Elsevier/Morgan Kaufmann, Amsterdam; Boston.

Soares de Lima, E.E., Feijó, B., Furtado, A.L., Pozzer, C.T., Ciarlini, A.E.M., 2010. Director of Photography and Music Director for Interactive Storytelling, in: Games and Digital Entertainment (SBGAMES), 2010 Brazilian Symposium on. Presented the Games and Digital Entertainment (SBGAMES), 2010 Brazilian Symposium on, pp. 129-137. doi:10.1109/SBGAMES.2010.13

Tactical Haptics. Reactive Grip ${ }^{T M}$ Tactile Shear Feedback.

Valente, L., de Souza, C.S., Feijó, B., 2008. An Exploratory Study on Non-visual Mobile Phone Interfaces for Games, in: Proceedings of the VIII Brazilian Symposium on Human Factors in Computing Systems, IHC '08. Sociedade Brasileira de Computação, Porto Alegre, Brazil, Brazil, pp. 31-39. 